\title{
Comparison of capacitive and inductive sensors designed for partial discharges measurements in electrical power apparatus
}

\author{
Michat Kunicki ${ }^{1, *}$ \\ ${ }^{1}$ Opole University of Technology, ul. Prószkowska 76, 45-758 Opole, Poland
}

\begin{abstract}
In the paper results of simultaneously conducted measurements achieved using capacitive and inductive sensors are presented according to different PD model sources immersed in a mineral transformer insulation oil. All measurements are preceded under laboratory conditions using typical measurement set up commonly applied for on-site PD detection: measuring impedance and capacitor and high frequency current transformer (HFCT) are used respectively. Measuring frequency and voltage level influence as well as phase resolved PD patterns analysis are investigated in the research. Various fundamental PD signal descriptors assigned for selected frequencies are also proposed and compared for chosen sensors. The main purpose of the presented research is to compare PD measurement results achieved using selected type of sensors during laboratory measurements and to point the best application areas in fields of PD detection in high voltage apparatus under normal operating conditions. Furthermore a proper measurement results interpretation coming from different sensors as well as measurement conducting problems and achieved patterns disparities are also discussed in the paper
\end{abstract}

\section{Introduction}

Monitoring of electrical power apparatus insulation system condition is a crucial item of fleet maintenance policy according to their reliability as well as providing a continuous electrical power supply for costumers [1-3]. Due to insulation system ageing process some degradation of dielectrics may occur which usually leads to local partial discharge (PD) generation. PD detection is proved to be one of the most effective insulation condition monitoring tools. There are many well-known and widespread PD detection methods but only electrical method (EM) supports a calibrated apparent charge measurement [4-9]. Measurement methodology and procedures are described in IEC 60270 standard. A phase resolved PD pattern (PRPD) has been widely known as an essential tool for a PD analysis provided by the EM. Measured apparent charge values and phase angle of the power voltage cycle correlation have been supported by the PRPD. Not only the highest effectiveness but also analysis capabilities of the measured phenomena have been delivered by a PRPD pattern tool [10-14]. A stochastic nature of a PD phenomena has been the highest challenge for all of PD measurement methods so far. Most of the physical quantities values registered during a measurement tightly depend on the PD source nature as well as on environment conditions. Any modification of the environment or the PD generation conditions radically affect the final measurement results. Thereunder in order to provide an adequate measurement results interpretation an objective comparison of achieved data with representative database need to be supported. In most cases an individual, relative measurement result is not an explicit and its interpretation may differ with reference to different apparatus or environment conditions [15-17]. Generally there are two sensor types designed for PD detection in EM method: inductive (Fig.1) and capacitive (Fig. 2) ones.

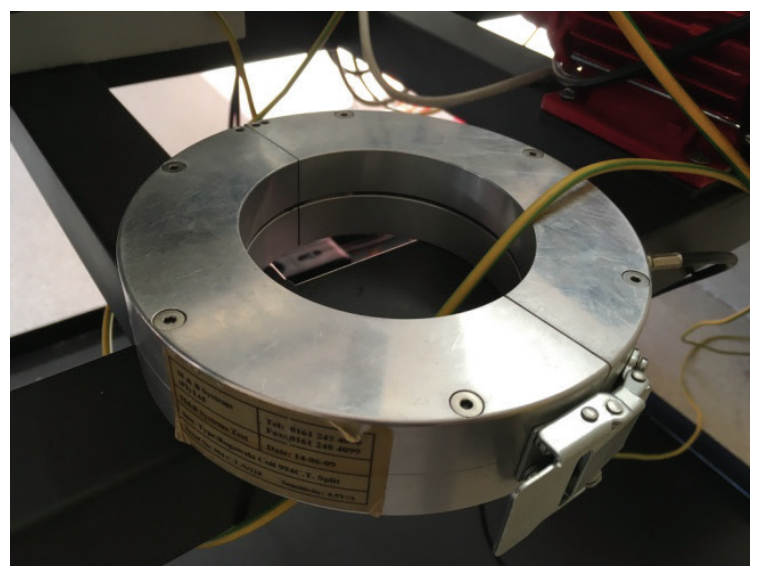

Fig. 1. General view of an inductive sensor (HFCT).

Some of capacitive sensors main fields of applications are e.g. power transformers, motors, generators and switchgears, while inductive sensors are usually used for cable applications $[11,18,19]$. One of the most significant advantages of inductive sensor is relatively high safety level during measurements yielded for the testing team - it does not require a direct high voltage connection: HFCT is to be clamped around the tested

Corresponding author: m.kunicki@po.opole.pl 
cable or grounding. Although a direct high voltage connection need to be supported during capacitive coupling PD measurements a HFCT cannot be applied for not insulated active parts, such as power lines or live clamps. Furthermore, different voltage supply phase occurred PD sources discrimination is also impeded while single HFCT grounding measurement is applied $[20,21]$.

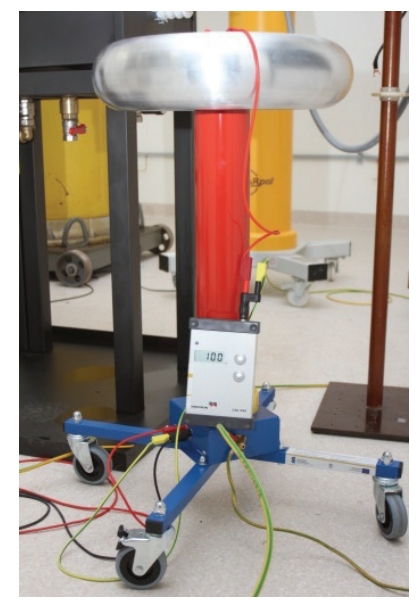

Fig. 2. General view of a capacitive sensor.

PD measurement results achieved using selected type of sensors during laboratory measurements comparison and the best application areas in fields of PD detection in high voltage apparatus under normal operating conditions recommendations have been the main purpose of the presented research.

Furthermore a proper measurement results interpretation coming from different sensors as well as measurement conducting problems and achieved patterns disparities have also been discussed in the paper.

\section{Research methodology}

All presented research has been preceded under laboratory conditions. Two electrode configurations have been selected for PD source modeling: point to point ( 8 mm gap) and surface type. A PD model source has been immersed in steel tank filed with brand new mineral insulation oil, commonly used for paper-oil insulation systems in contemporary electrical power transformers. A high voltage (HV) has been supplied by the test transformer with a ratio $220 / 110000$.

A HV level has been adjusted using the automatic voltage control unit, connected to the primary winding of the test transformer (Fig. 3). In case of the surface type configuration a plate electrode has been grounded and 8 $\mathrm{mm}$ thick pressboard plate has been used as a solid dielectric. Two-track layout MPD600 system from Omicron has been applied for the research.

The first - capacitive - measuring track has consisted of a coupling capacitor MCC210 with $1 \mathrm{nF}$ of capacity, a CPL542A quadripole with $30 \mu \mathrm{F}$ of capacity (used for impedance measuring also), a MPD600 module equipped with battery power supply and a MCU504 control unit.

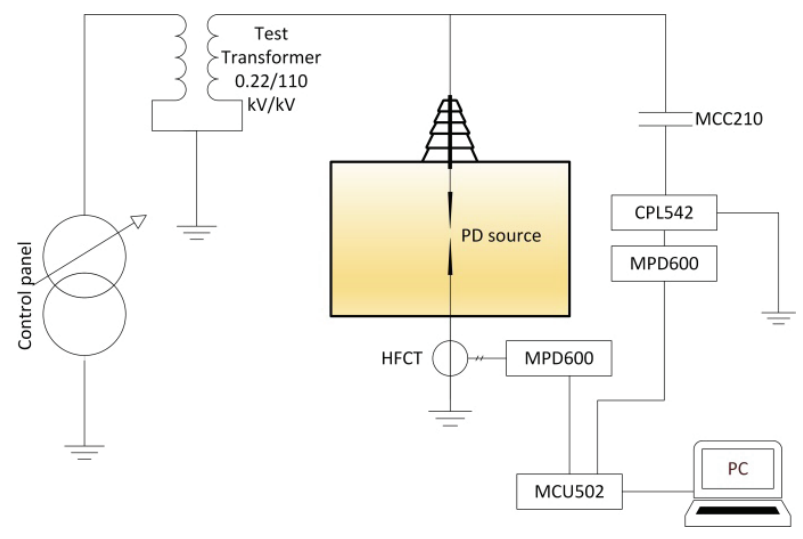

Fig. 3. Measuring system layout.

The second - inductive - measuring track has consisted of HFCT - Rogowski coil 994C.T.Split from M\&B Systems Ltd, with its sensitivity of $4.5 \mathrm{~V} / \mathrm{A}$, connected to the other MPD600 module and MCU504. A MPD software has been used for phase resolved PD patterns (PRPD) acquisition. All PD data have been recorded by a $\mathrm{PC}$ in order to further post-measurement analysis. According to a noise free laboratory environment no supplementary filtering has been applied during measurements. All measurements have been proceeded with two types of sensors simultaneously. A voltage level influence on measurements results as well as measuring frequency band have been investigated in the research. Three voltage levels between 23 and $31 \mathrm{kV}$ have been applied and three frequencies: $0.4,2,6 \mathrm{MHz}$ for each electrode configuration. The integration window width has been set to $400 \mathrm{kHz}$ for both channels and has not been adjusted during all measurements. Capacitive as well as inductive measuring channels have been calibrated with CAL542 charge calibrator using $1 \mathrm{nC}$ charge injection.

\section{Results and discussion}

Survey analysis based on amplitude spectra comparison during PD generation achieved for selected electrode configurations has been the first step of the research. Exemplary amplitude spectra results have been presented in Fig. 4. High convergence of signals registered using different sensors may by noticed below approx. $10 \mathrm{MHz}$ in case of both applied electrode configurations, and a relative signals variation has not exceeded $5 \mathrm{~dB}$. Results achieved for surface type electrode configuration have been found relevant up to approx. $20 \mathrm{MHz}$. In case of point-point configuration a high disparity has been observed for frequencies over 10 $\mathrm{MHz}$ where relative signals variation reached even 20 dB. Similar situations have been indicated for all applied voltage levels.

In Fig. 5 there have been presented some exemplary PRPD patterns obtained for $24 \mathrm{kV}$ powered point-point configuration and a frequency of $0.4 \mathrm{MHz}$. A high similarity might be observed according to PRPD shape as well as phase domain position of PD occurring and apparent charge levels of signals registered by selected sensors. 
a)
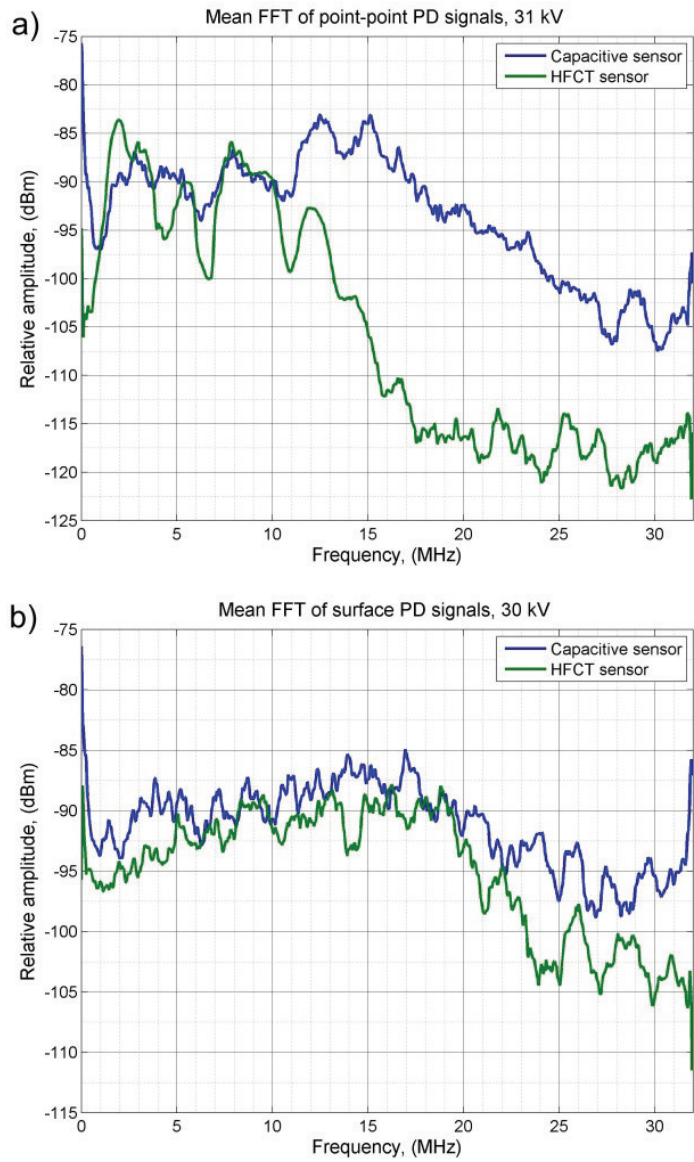

Fig. 4. Exemplary amplitude spectra of signals generated by PDs registered using selected sensors: a) point to point electrode $31 \mathrm{kV}, \mathrm{b}$ ) surface type electrode $30 \mathrm{kV}$.

Nevertheless some differences have been noticed. Capacitive sensor captured apparent charge values have been found approx. 10\% higher than inductive ones. Also a grind derived interference noise significantly visible in case of capacitive sensor results has not appeared on HFCT patterns. Form the power grid point of view an electrode has been read as a circuit discontinuity, so interferences have been cut off the grounding and a PD signal has been the only registered by the sensor. The capacitor has been connected by the $\mathrm{HV}$ side so it has captured PD signals as well as grind derived interference.

Point-point configuration exemplary PRPD results achieved for $31 \mathrm{kV}$ and a frequency of $6 \mathrm{MHz}$ have been presented in Fig. 6. The most significant disparities have been recognized during that measurements, especially according to apparent charge dynamics and registered values. A mean apparent charge value when capacitive sensor had been applied has amounted approx. $15 \mathrm{pC}$ while result for HFCT sensor has been $170 \mathrm{pC}$. Also a max apparent charge values comparison has resulted in the same disparities: about $60 \mathrm{pC}$ for capacitive and over $1 \mathrm{nC}$ for HFCT one sensors respectively.

The described observation has not depended on an applied voltage level, and has repeated during all measurements for $6 \mathrm{MHz}$ and point-point configuration. Despite charge dynamics differences a phase domain PD
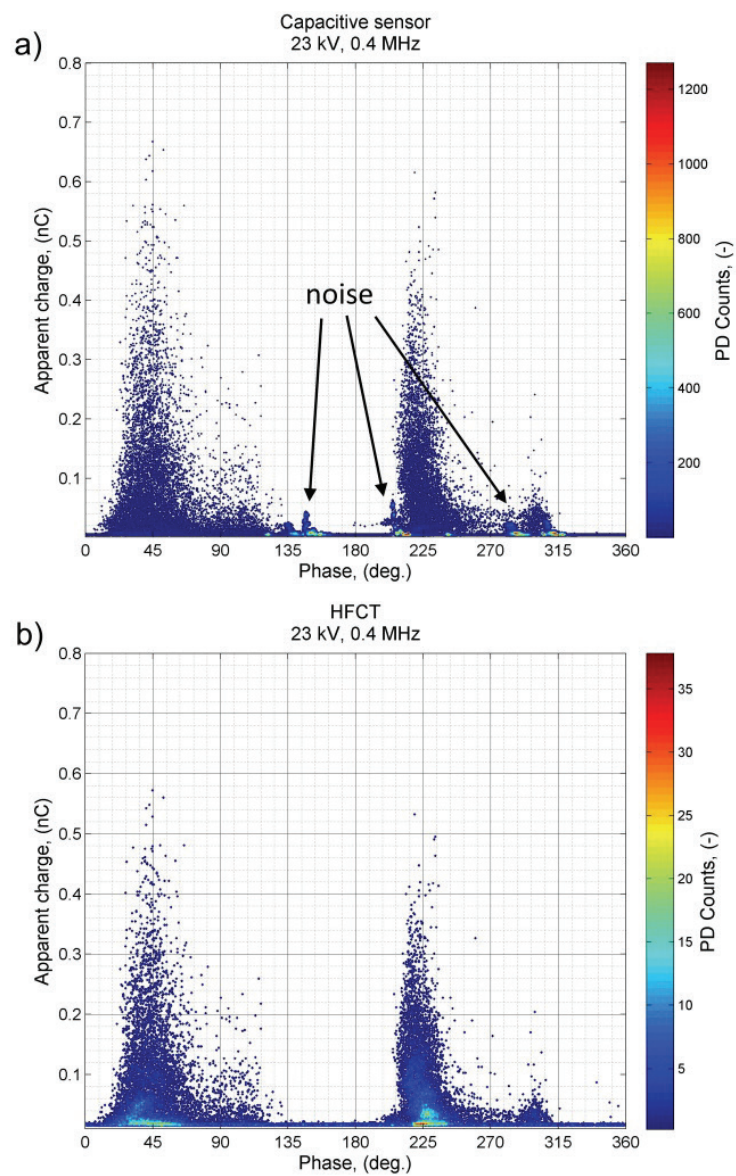

Fig. 5. Exemplary PRPD patterns registered using selected sensors for $23 \mathrm{kV}, 0.4 \mathrm{MHz}$ (point to point electrode): a) capacitive sensor, b) HFCT sensor.

activity has been found convergent: PD occurring phase angle range according to the first and second supply voltage half-periods $\left(10^{\circ}-80^{\circ}\right.$ and $\left.190^{\circ}-260^{\circ}\right)$ as well as phase angles related to max apparent charge values within both half-periods $\left(40^{\circ}\right.$ and $\left.220^{\circ}\right)$. Also a PD density results have been identified as very similar. No additional noise interferences have been noticed.

Surface type electrode configuration comparative measurements have been the next stage of the presented research. Some exemplary PRPD patterns registered using selected sensors for $24 \mathrm{kV}$ and $0.4 \mathrm{MHz}$ have been illustrated in Fig. 7.

Conclusion has been similar to the one presented according to the previous electrode and a frequency of $0.4 \mathrm{MHz}$ : selected sensors registered signals high similarity might be observed; capacitive sensor captured apparent charge values have been found approx. 10\% higher than inductive ones; a grind derived interference noise significantly visible in case of capacitive sensor results has not appeared on HFCT patterns. The described situation has not been influenced by the voltage level adjustments. Comparing PRPD patterns registered for selected electrode configurations some obvious differences have been observed: different PRPD shapes have been associated with each electrode, also a different share of PD activity within each half-period has been pointed. 

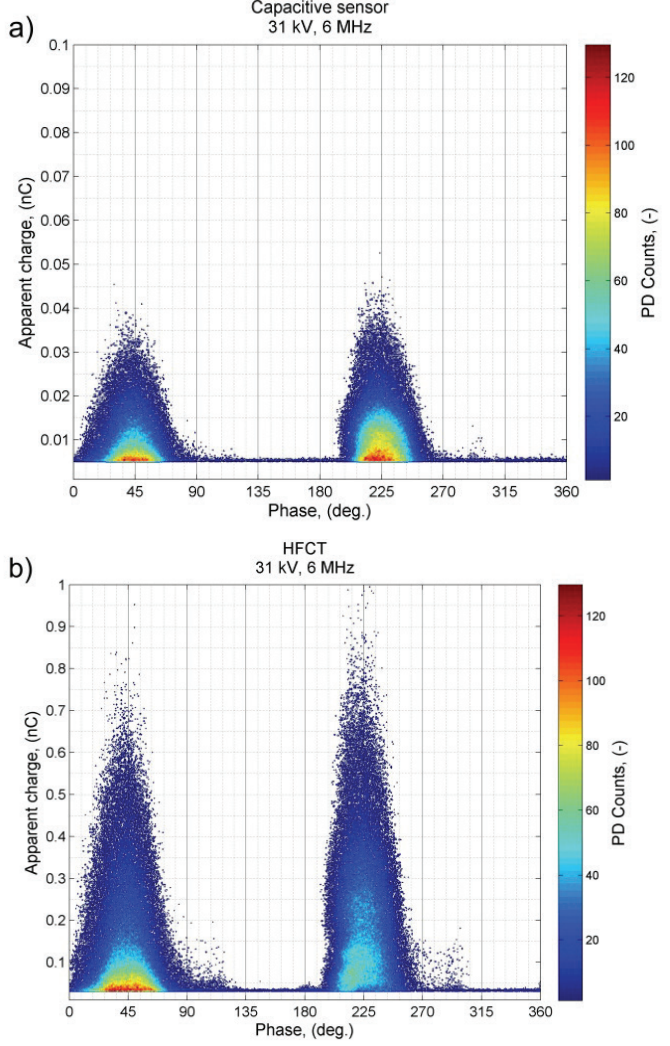

Fig. 6. Exemplary PRPD patterns registered using selected sensors for $23 \mathrm{kV}, 6 \mathrm{MHz}$ (point to point electrode): a) capacitive sensor, b) HFCT sensor.
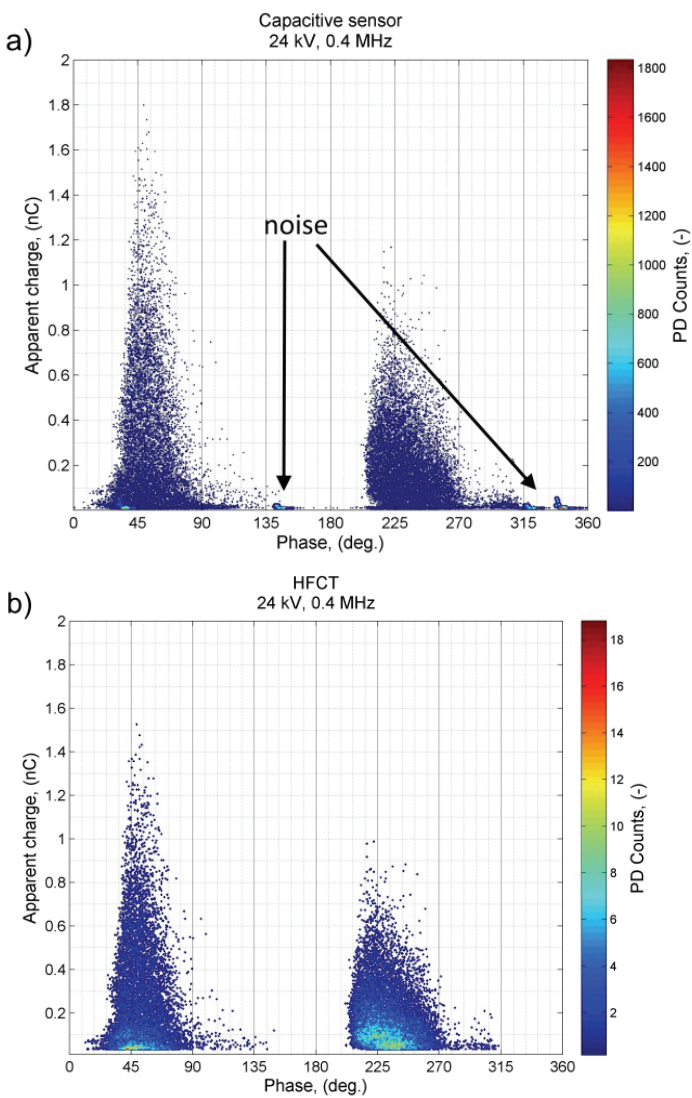

Fig. 7. Exemplary PRPD patterns registered using selected sensors for $24 \mathrm{kV}, 0.4 \mathrm{MHz}$ (surface type electrode): a) capacitive sensor, b) HFCT sensor.
In Fig. 8 there have been presented measurement results captured for surface type configuration with a voltage of $30 \mathrm{kV}$ and a frequency of $2 \mathrm{MHz}$. Selected sensors registered signals high similarity might be observed according to PRPD shape as well as phase domain PD occurring. Also a PD density results have been found as very similar. No additional noise interferences have been noticed according to all previous results achieved for all frequencies above $1 \mathrm{MHz}$. Nevertheless some significant mismatches have been pointed in relation to apparent charge amplitudes while different sensors results had been compared. Generally approx. $40 \%$ of amplitudes variations have been observed: max apparent charge values within the first half-period have reached about $2.3 \mathrm{nC}$ and over $3 \mathrm{nC}$ in case of capacitive and inductive sensors applications respectively. The same trend has been found according to the second half-period: max apparent charge values have reached about $1.5 \mathrm{nC}$ and over $2.5 \mathrm{nC}$ in case of capacitive and inductive sensors applications respectively. However a PD density results have been identified as very convergent. No voltage level influence on described properties has been noticed during research in case of surface type configuration.
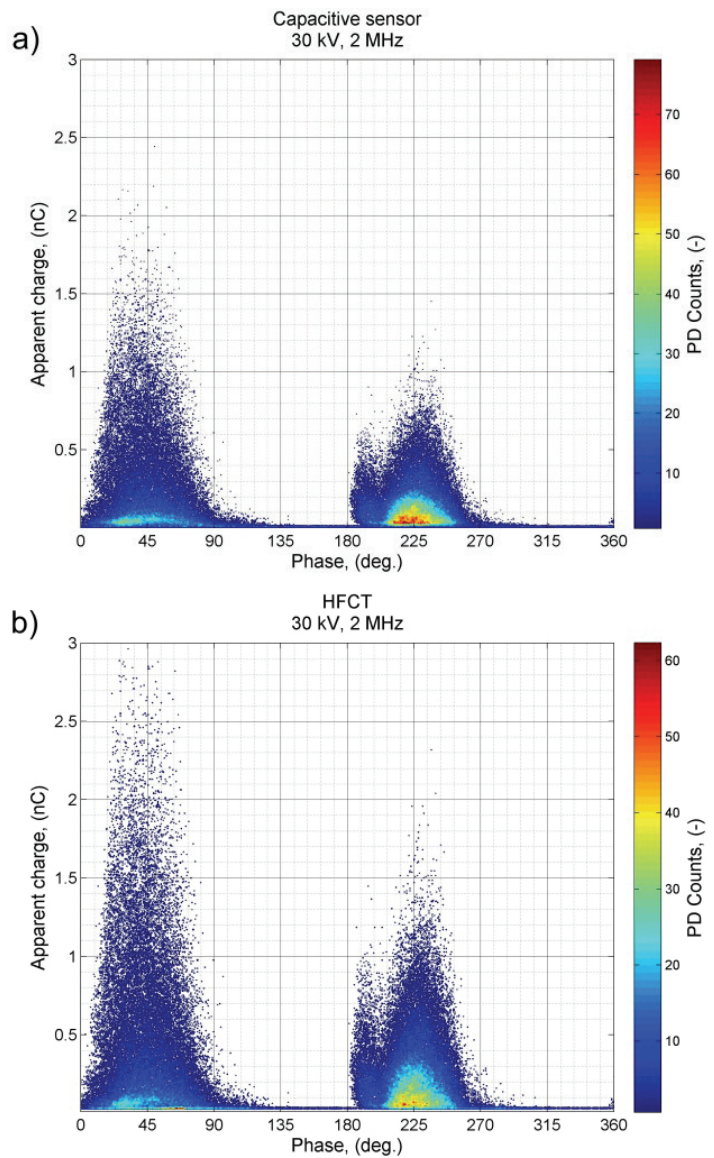

Fig. 8. Exemplary PRPD patterns registered using selected sensors for $30 \mathrm{kV}, 2 \mathrm{MHz}$ (surface type electrode): a) capacitive sensor, b) HFCT sensor.

\section{Conclusions}

Nowadays a PD diagnostics for sure has been found one of the crucial nexus of electrical power distribution 
systems. Despite there are various commonly known and widespread PD testing methods an improvement of every of them has still been a current issue, especially in the aspects of measurement results interpretation as well as a testing methodology, simplifying and calibration, above all, an on-site application during an apparatus normal service. Furthermore, advanced PD testing tools purchase costs need also to be considered. In the presented paper various exemplary representative measurement results as well as results analysis have been showed. It has been confirmed that PD measurement results achieved using capacitive and inductive sensors simultaneously have not been influenced by supply voltage level, no matter what electrode configuration had been applied. Nevertheless a significant dependency on measuring frequency has been indicated during research. Only result achieved in measuring conditions related with IEC60270 (0.4 MHz) have showed an accepted consistence level.

On the grounds of the presented conclusion, above described research on-site verification as well as a more detailed calibration issue have seemed to be the next aim of the investigation that are to be proceeded by the author as a further study and development on the described problem.

The work was co-financed from funds of the National Science Centre, Poland as a part of the Preludium Research Project No. 2015/19/N/ST8/03909.

\section{References}

1. T. Boczar, A. Cichoń, S. Borucki, IEEE Trans. Dielectr. Electr. Insul. 21, 854-865 (2014)

2. S. Borucki, IEEE Trans. Power Deliv. 27, 670-676 (2012)

3. J. Buchacz, A. Cichon, J. Skubis, IEEE Trans. Dielectr. Electr. Insul. 24, 552-558 (2017)

4. D. Zmarzly, L. Nagi, S. Borucki, T. Boczar, Acta Phys. Pol. A 125, 1377-1379 (2014)

5. Ł. Nagi, D. Zmarzły, T. Boczar, P. Frącz, IEEE Trans. Dielectr. Electr. Insul. 23, 2036-2041 (2016)

6. M. Kozioł, D. Wotzka, T. Boczar, P. Frącz, J. Spectrosc. 1814754, (2016)

7. D. Wotzka, A. Cichoń, T. Boczar, Arch. Acoust. 37, 19-22 (2012)

8. T. Boczar, S. Borucki, A. Cichoń, D. Zmarzły, IEEE Trans. Dielectr. Electr. Insul. 16, 214-223 (2009)

9. T. Boczar, A. Cichoń, D. Wotzka, M. Kunicki, M. Kozioł, IEEE Trans. Dielectr. Electr. Insul. 24, 120-128 (2017)

10. M. Majidi, M. Oskuoee, Electr. Power Syst. Res. 119, 100-110 (2015)

11. R. Sarathi, I. Merin Sheema, J. Rajan, IEEE Trans. Dielectr. Electr. Insul. 21, 674-682 (2014)

12. A. Kraetge, S. Hoek, M. Koch, W. Koltunowicz, IEEE Trans. Dielectr. Electr. Insul. 20, 2043-2051
(2013)

13. M. K. Chen, J. M. Chen, C. Y. Cheng, IEEE Trans. Dielectr. Electr. Insul. 21, 1405-1414 (2014)

14. S. Coenen, S. Tenbohlen, IEEE Trans. Dielectr. Electr. Insul. 19, 1934-1940 (2012)

15. P. Piekielny, A. Waindok, in International Symposium on Electrodynamic and Mechatronic Systems (SELM), Zawiercie, 15-18 May 2013 5152 (2013)

16. M. Kunicki, A. Cichoń, S. Borucki, Arch. Acoust. 41, 265-276 (2016)

17. G. Dombek, Z. Nadolny, Eksploat. i Niezawodn. Maint. Reliab. 19, 62-67 (2017)

18. F. Álvarez, F. Garnacho, J. Ortego, M. Á. SánchezUrán, Sensors 15, 7360-7387 (2015)

19. M. Shafiq, G. A. Hussain, L. Kutt, M. Lehtonen, Measurement 49, 126-137 (2014)

20. J. Seo, H. Ma, T. Saha, IEEE Trans. Dielectr. Electr. Insul. 22, 1105-1117 (2015)

21. A. Cavallini, X. Chen, G. C. Montanari, IEEE Trans. Power Deliv. 25, 814-824 (2010)21. 